\section{Evolution wins out in Hong Kong curriculum dispute}

Hong Kong's Education Bureau has vindicated biologists - and disappointed creationists - by clarifying its guidelines for teaching biology in secondary schools.

Debate had been raging since February over the revamped curriculum, to go into effect in September, which "in addition to Darwin's theory" encourages the teaching of "other explanations for evolution and the origins of life". Some scientists worried the clause implied support for creationism and intelligent design, which are already taught in many of Hong Kong's religious schools (see Nature 457, 1067; 2009).

A five-page clarification, released on 22 June, said that studies of the origin of life should focus on Darwinism and that "other explanations" referred to alternative theories of evolution, such as those put forth by JeanBaptiste Lamarck and Alfred Russel Wallace.

The biology curriculum does not include the teaching of creationism, intelligent design and "non-scientific explanations", the document says. Teachers may still choose to cover topics beyond the guidelines, however.

\section{Japanese diplomat chosen to lead nuclear watchdog}

The International Atomic Energy Agency (IAEA) voted in Japan's Yukiya Amano as its next director general on 2 July. Amano, 62 , won the necessary two-thirds majority of the IAEA's 35-member board by a single vote to beat chief rival Abdul Samad Minty of South Africa, considered a favourite of the non-nuclear-weapons countries.

Based in Vienna, the IAEA is the international body charged with policing the nuclear-nonproliferation treaty (NPT), the primary agreement meant to halt the spread of nuclear weapons.

Amano is a lawyer by training and has an extensive background in disarmament

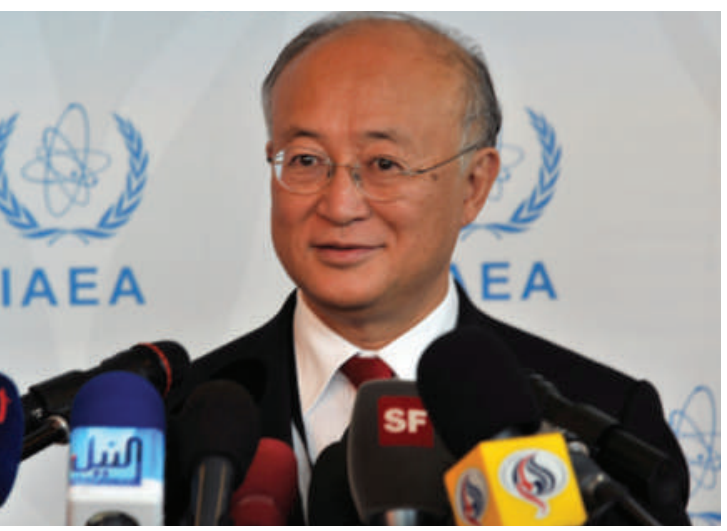

Yukiya Amano will head efforts to police the spread of nuclear weapons.

\title{
Lunar Reconnaissance Orbiter snaps test pictures
}

All is going smoothly so far for NASA's Lunar Reconnaissance Orbiter, which launched on 18 June. On 2 July it captured its first high-resolution test images of the Moon (pictured right), kicking off a year-long mapping mission.

Regular updates from the orbiter can be found on its Twitter feed (http:// twitter.com/LRO_NASA).

Meanwhile, Nature is twittering the Apollo 11 Moon mission as it happened in real time -40 years on (http://twitter.com/ ApolloPlus40).

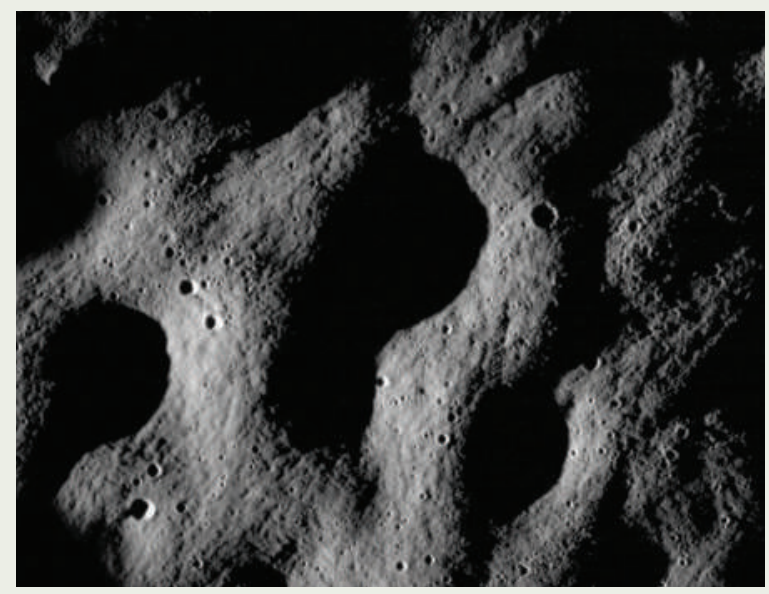

and nonproliferation. Pending final approval in September by the 146-member IAEA general conference, he will succeed Mohamed ElBaradei, who has led the agency since 1997 and who along with the agency received the 2005 Nobel Peace Prize. With a reputation for a quiet, lowkey style, Amano is unlikely to have the profile of ElBaradei, whose occasionally inflammatory comments made headlines. For a longer version of this story, see http://tinyurl. com/ndz808

\section{Governments fail to reduce global biodiversity decline}

Governments worldwide are failing their commitments to reduce biodiversity loss by 2010 , according to a report released last week by the International Union for Conservation of Nature (IUCN).

The IUCN's analysis of its 2008 global 'Red List' of threatened species uses indices to track trends in extinction risk. Birds, mammals, amphibians and corals all showed a continuing deterioration, it says.

The United Nations has declared 2010 the international year of biodiversity, under its Convention on Biological Diversity. On 26 June, European Union (EU) environment ministers meeting in Luxembourg said they were "deeply concerned" by a European Commission assessment in December stating that the EU is unlikely to meet its own ambitious aim of halting biodiversity loss by 2010 .

\section{US scientist jailed for sharing sensitive data}

A former University of Tennessee professor has been sentenced to four years in prison for sharing sensitive technologies with his Chinese and Iranian graduate students. J. Reece Roth, an emeritus professor of electrical engineering, was sentenced on 1 July by a Tennessee district court for violating the Arms Export Control Act. He had been developing ways to reduce the drag on unmanned planes, and employed two research assistants without obtaining the required licence (see Nature 442, 232$233 ; 2006)$. Roth plans to appeal the verdict.

In a separate case, a Chinese-born scientist who has lived in the United States for 23 years is suing the US government for rights violations for expelling him last year from the NASA Ames Research Center, California.

Haiping $\mathrm{Su}$, a US citizen who received his doctorate in 1991 from Kansas State University in Manhattan, alleged in a case filed on 24 June in a San Jose federal court that a 2007 security badge-issuing process led to his illegal ousting.

Su was working on airborne systems for imaging forests. His attorneys say he had no involvement with classified material.

\section{US Air Force will continue to share meteor data}

The United States Air Force says that it will resume sharing data on incoming meteors with astronomers.

The Air Force collects the data with a network of satellites and sensors designed as a missile early-warning system. For more than a decade, it provided them to astronomers on an ad-hoc basis, but the informal relationship came to a halt earlier this year (see Nature 459, 896-897; 2009).

Astronomers feared that the Air Force had put a stop to the practice, but "the data will still flow", says Andy Roake, a spokesman for Air Force Space Command in Colorado Springs, Colorado. The Air Force is developing procedures for releasing data that will be faster, more systematic and in compliance with classification procedures. Data sharing could resume within the next few months. 